\title{
Cell therapy-processing economics: small-scale microfactories as a stepping stone toward large-scale macrofactories
}

\author{
Richard P Harrison ${ }^{* 1,2,4}$, Nicholas Medcalf ${ }^{1}$ \& Qasim A Rafiq ${ }^{3,4}$ \\ ${ }^{1}$ Centre for Biological Engineering, Holywell Park, Loughborough University, Loughborough, LE11 3TU, UK \\ ${ }^{2}$ Wolfson Centre for Stem cells, Tissue Engineering \& Modelling (STEM), The University of Nottingham, Centre for Biomolecular \\ Sciences, University Park, Nottingham, NG7 2RD, UK \\ ${ }^{3}$ Department of Biochemical Engineering, Faculty of Engineering Science, University College London, Gower Street, London, \\ WC1E 6BT, UK \\ ${ }^{4}$ Department for Biochemical Engineering, School of Life \& Health Sciences, Aston University, Aston Triangle, Birmingham, B4 7ET, \\ UK \\ * Author for correspondence: Tel.: +44 (0)1509 564891; R.P.Harrison@Lboro.ac.uk
}

\begin{abstract}
Aim: Manufacturing methods for cell-based therapies differ markedly from those established for noncellular pharmaceuticals and biologics. Attempts to 'shoehorn' these into existing frameworks have yielded poor outcomes. Some excellent clinical results have been realized, yet emergence of a 'blockbuster' cellbased therapy has so far proved elusive. Materials \& methods: The pressure to provide these innovative therapies, even at a smaller scale, remains. In this process, economics research paper, we utilize cell expansion research data combined with operational cost modeling in a case study to demonstrate the alternative ways in which a novel mesenchymal stem cell-based therapy could be provided at small scale. Results \& Conclusions: This research outlines the feasibility of cell microfactories but highlighted that there is a strong pressure to automate processes and split the quality control cost-burden over larger production batches. The study explores one potential paradigm of cell-based therapy provisioning as a potential exemplar on which to base manufacturing strategy.
\end{abstract}

First draft submitted: 18 July 2017; Accepted for publication: 6 December 2017; Published online: 6 March 2018

Keywords: automation • bioprocessing • cell expansion • cell factories $\bullet$ cost of goods (COG) • manufacturing • process economics $\bullet$ stem cell therapy

Cell-based therapies have the potential to provide curative treatment to a multitude of conditions, which currently have a high degree of unmet need [1]. The first real success for cell-based therapies was the bone marrow transplant in the mid-1950s [2]. With the discovery of human leukocyte antigen-typing and bone marrow-derived stem cells [3], this procedure moved from being a dangerous experimental approach to routine treatment and has pushed the cell therapy field forward rapidly. More recently, increasing knowledge of the immune system has facilitated the discovery of allogeneic or 'universal' cell therapies able to treat multiple patients with a single source [4].

Mesenchymal stem cells (MSCs) are a focus of this intense research and large expectations have been placed on this cell type to fulfill a variety of roles [5]. These include not only regeneration of tissue [6] but also more general immunomodulatory [7], anti-inflammatory [8] or trophic secretion [9] effects to indirectly assist other cells or tissues.

The clear benefit of approaching MSC therapy through an allogeneic approach rather than autologous is through enhanced scalability of production with attendant cost savings [10]. Sourcing therapeutic starting material from healthy donors and then using this to treat unhealthy patients is an attractive paradigm not only from a patient perspective but also from a process design perspective with obvious benefits in reliability, storage and availability [11].

It is perhaps unsurprising that a number of companies are using this approach for clinical products (Cartistem ${ }^{\circledR}$ [Medipost, Seoul, South Korea] and Prochymal ${ }^{\circledR}$ [Osiris/Genzyme, MD, USA]) [12]. Despite some setbacks with the product development cycles of many cell-based therapies [13], those involved are convinced the therapeutic offering is meritworthy [14]. Additionally, the historical perspective should not be forgotten. In the 1940s, cortisone 
production nearly bankrupted Merck and penicillin barely yielded any profit to its manufacturers [15]. Despite this challenging start, the pharmaceutical industry proceeded to become arguably the greatest industry of our time both from the perspective of transforming lives and generating wealth [16].

The strong clinical demand has triggered intense interest around manufacturing feasibility and cost of goods (COG) [17]. Previous studies have demonstrated good reasons to move toward scalable culture platforms in order to meet the projected dose volumes for Prochymal [18]. As our understanding of mechanism of action has improved, it has become clearer that more is not always better when it comes to dose size and cell number [19]. This is caused by the potential for rapid cell loss postimplantation if dose sizes are too great [20]. Indeed, formulation is likely to be the key to reliable posology and in some cases smaller doses have been shown to be more efficacious than larger ones [21]. Although the data are so far inconclusive, allogeneic-sourced MSCs rather than autologous may actually yield better clinical efficacy in certain scenarios [22].

The regenerative medicine industry has long awaited a 'blockbuster' product to act as both an example of, and a template for the difficult product development process [23]. After more than a decade, we are still waiting, and while isolated cases of clinical success are reassuring, even small commercial successes will reinvigorate the field. Based on the emerging findings around dose and response, this article reports on a case study investigating the feasibility of manufacturing lower dose allogeneic MSC therapies at a smaller scale (2500 doses/annum) that we believe is more in line with realistic clinical expectations and prudent commercial practice.

\section{Materials \& methods \\ Overview}

A graphical user interface-based COG model was developed using the Microsoft ${ }^{\circledR}$ Excel $^{\text {TM }}$ (Microsoft Corporation, WA, USA) platform with integrated Visual Basic ${ }^{\text {TM }}$ for applications (Microsoft Corporation) script for enhanced data handling. The COG model utilizes a database of values combined with user specified variances to predict technical manufacturing outputs as well as financial performance over a period from 1 to $25+$ years.

MSCs were chosen as the exemplar cell type for this study. The findings presented are broadly applicable to other adherent cell populations. Certain cell types may exhibit lower levels of contact inhibition or grow to a higher density due to size differences. Culture of small cells such as pluripotent stem cells, for example, would grow to significantly higher density due to their comparatively small size of $2-3 \mu \mathrm{m}$ [24] as opposed to $20-30 \mu \mathrm{m}$ for MSCs [25]. This can result in yields of 10+ fold greater yet the manufacturing process steps are likely to vary from MSCs.

\section{Model design}

The COG model was designed to estimate manufacturing capacity required at a central facility based on total patient doses required per year. An estimate of demand for biological characterization of the cell sources was used to establish lot size yield projections and to establish the resource consumption and equipment requirement for the upstream and downstream processes. Baseline values for facility size, office space and staffing requirements were established in the model based upon pragmatic assumptions. These values were automatically optimized further depending on the process requirements established by the model. COG of a particular process configuration consisted of annual direct costs (materials, labor staffing and quality control [QC]) and indirect costs (facility and equipment costs and loan servicing). Facility and equipment were amortized over 10 years. Loan agreements were assumed at 10 years with a conservative $5 \%$ interest rate.

COG dose values were established as follows:

$$
C o G / \text { dose }=\sum \frac{\text { annual materials }+ \text { annual labour }+ \text { annual } Q C+\text { indirect costs }}{\text { annual doses produced }}
$$

$$
\frac{C o G}{D o s e}=\sum \frac{m+l+q+i}{d}
$$


Material costs were further broken down into wet and dry consumables to examine the granular detail of material COG. Material costs were established by:

$$
\text { annual materials }=(\text { dry consumables }+(\text { wet consumables } \times \text { usage })) \text { lots }^{\text {annual }}
$$

where dry consumables consist of all vessels and accessories. Wet consumables consist of all medium, buffers and coating factors multiplied by usage. Usage of both dry and wet consumables varied according to the expansion potential of the donor cell type and the media used for culture. Thus, 'usage' was dynamically calculated based off the number of vessels required to maximally culture a given batch to its full expansion potential as informed by the growth characteristics in the experimental in vitro culture. This combined total per lot produced is further multiplied by lots produced per annum.

Labor costs are calculated as salary plus yearly training costs as follows:

$$
\text { annual labour }=\sum(\text { salary band }+ \text { overheads }+ \text { training costs }) \text { number of staff in band }
$$

where the salary band is the base salary cost for that level of employee, overheads are the indirect annual costs of employing that staff member such as pension contributions and training costs are the annual costs of maintaining the training level for that salary band. These costs are multiplied by the number of staff within the band and the sum total of all bands is calculated for yearly staffing costs.

Training costs are calculated as base costs for all staff members as follows:

$$
\text { annual training }=\sum((\text { salary band }+ \text { multiplier }) \text { number of staff in band })
$$

where the salary band is assigned a training multiplier to budget for training expenditure and all bands are totaled per year for annual costs. Additional training expenditure is applied for operators due to the rigorous and costly training programs they receive and the need under GMP to show that training is refreshed at intervals. Additional training costs for operators and QC staff are applied as follows:

$$
\text { operator training }=\frac{\text { number of training runs } \times \text { lot production } C o G}{\text { staff turnover }}
$$

where training runs are the number of full costed runs required to become proficient, the lot production COG is the cost of producing one full product lot and staff turnover is the amortized cost of retraining staff given expected ongoing recruitment cycles.

Indirect costs are presented as facility costs and equipment costs amortized over a set duration. Total costs can be treated as capital expenditure with no additional costs or asset percentage accessed as a loan over a set period.

$$
\text { annual indirect costs }=\frac{\text { facility costs }+ \text { equipment costs }+ \text { maintenance costs }}{\text { amortisation period }}+\frac{\text { loan amount }}{\text { loan duration }}
$$

A table of process and cost assumptions used within the model are detailed in Table 1. Further assumptions are detailed in Supplementary Tables 1-3. The interest rate chosen for this case study was assumed at $5 \%$ and the value of loan required assumed to be $75 \%$. These total costs were amortized over a duration of 10 years. No discount factors were applied. It is important to note that these key assumptions were made for the individual process examined in this research case study and these will change for any given manufacturing process.

\section{MSC culture}

MSC population expansion potential was assessed for three bone marrow-derived donors. Cells were expanded in monolayer to establish the variation in expansion potential between donor lines as well as the maximum achievable lot sizes over three expansion periods. Materials were purchased from Thermo Fisher Scientific (MA, USA) unless 
Table 1. Key process and cost assumptions used.

\begin{tabular}{|c|c|}
\hline Attribute & Figure \\
\hline \multicolumn{2}{|l|}{ Cell growth } \\
\hline Starting inoculation (total units) & 875,000 \\
\hline Seeding density $\left(5000 / \mathrm{cm}^{2}\right)$ & 5000 \\
\hline Culture duration (days) & 18 \\
\hline \multicolumn{2}{|l|}{ Culture environment } \\
\hline Incubator capacity (flasks) & 55 \\
\hline Free space minimum & $15 \%$ \\
\hline \multicolumn{2}{|l|}{ Finishing steps } \\
\hline Cost of fill and finish (US\$/dose) & 175 \\
\hline Cost of transport (US $\$ /$ dose) & 85 \\
\hline Cost of quality control per run (US $\$ /$ run) & 5926.53 \\
\hline Loan to value percentage & $75 \%$ \\
\hline Loan duration (years) & 10 \\
\hline Capital amortization period (years) & 10 \\
\hline Average interest rate & $5 \%$ \\
\hline
\end{tabular}

otherwise mentioned. Consumable volumes were calculated and used as $\mathrm{ml} / \mathrm{cm}^{2}$ as follows: $0.029 \mathrm{ml}$ (medium), $0.077 \mathrm{ml}$ (fibronectin coating), $0.077 \mathrm{ml}$ (TrypLE Express ${ }^{\top M}$ ) and $0.023 \mathrm{ml}$ (phosphate-buffered saline [PBS]). Cell counts were performed using an NC3000 ${ }^{T M}$ Nucleocounter $^{\circledR}$ (ChemoMetic, Copenhagen, Denmark)

\section{Culture of MSCs in serum-containing media}

Expansion of MSCs in serum-containing media (SCM) was performed in standard culture conditions $\left(37.5^{\circ} \mathrm{C}\right.$, $5 \%[\mathrm{v} / \mathrm{v}] \mathrm{CO}_{2}$ in air) in standard culture medium consisting of DMEM supplemented with $10 \%$ (v/v) fetal bovine serum (FBS), 1\% (v/v) non-essential amino acids (NEAA), $1 \mathrm{mM}$ L-glutamine, $1 \mathrm{mM}$ pyruvate and 1\% penicillin/streptomycin (stock 10,000 U/ml). Media were exchanged every $72 \mathrm{~h}$. Cells were passaged every 6 days using TrypLE Express at a seeding density of 5000 cells $/ \mathrm{cm}^{2}$.

\section{Culture of MSCs in serum-free media}

Expansion of MSCs in serum-free media (SFM) was performed in standard culture conditions $\left(37.5^{\circ} \mathrm{C}, 5 \%\right.$ [v/v] $\mathrm{CO}_{2}$ in air). Flasks were coated prior to seeding with PRIME-XV ${ }^{\circledR}$ Fibronectin (Irvine Scientific, CA, USA) at $5 \mu \mathrm{g} / \mathrm{ml}$ in PBS for $4 \mathrm{~h}$ at ambient temperature. Culture was performed in Irvine PRIME-XV xeno-free MSC medium (Irvine Scientific). Media were exchanged every 48 h. Cells were passaged every 6 days using TrypLE Express at a seeding density of 5000 cells $/ \mathrm{cm}^{2}$.

\section{Case study}

The manufacturing process outlined in this article addresses a theoretical allogenic or partially patient-matched MSC, cell-based therapeutic being manufactured in a centralized location and distributed to clinical locations. The benefit of choosing a universal donor-type therapeutic model rather than a patient-specific one is clear: one lot to one patient is increasingly challenging to manufacture and with this complexity comes significantly increased costs.

Scalable expansion technologies with multiple, isolated product streams are the key to realizing the promise of personalized autologous therapies [26], but these technologies are not yet ready for commercial success [11]. The case study presented here examines both manual processes and automated processes. The automated platform chosen is that of the SelecT ${ }^{T M}$ by Sartorius Stedim (Göttingen, Germany). This was chosen as it is a first-generationautomated platform that aims to translate the human actions associated with culture of cells to a robotic process. This is outlined in Figure 1. 


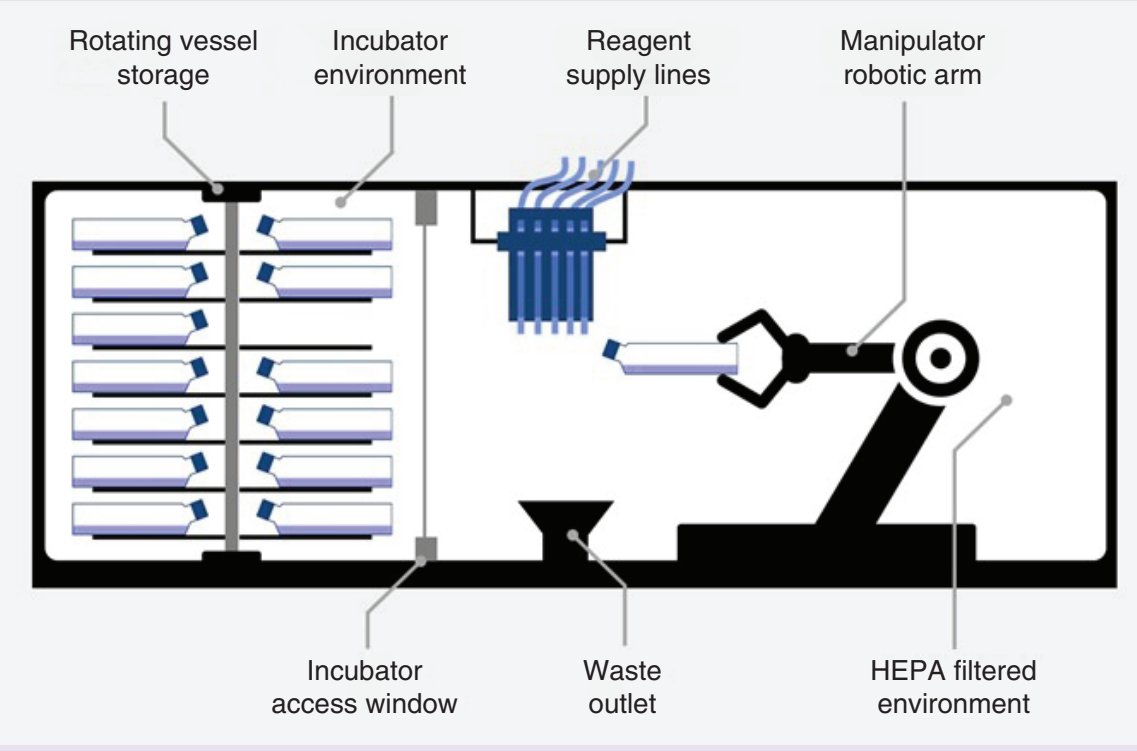

Figure 1. Diagrammatic representation of the SelecT ${ }^{T h}$ automated platforms by Sartorius Stedim.

The goal of this research is to evaluate the feasibility of scaling-out the manufacturing in planar format with manual or automated manipulations by examining the COG associated with the whole process. While this approach does not incur the savings from economy of scale that is promised by platforms that are used for scaling-up in single batches, it has a shorter development path from the research bench and is in some regard increasingly feasible for short-to-medium-term cell manufacturing. Similarly, the promise of cell therapies to treat a wide range of conditions have put estimates for demand at 500,000 doses/year [27]. The production capacity to meet these estimates has yet to emerge and instead products are being put through clinical trial using research-scale manufacturing methods [28], thus restricting their production method to the planar format if batch comparability is to be maintained. Thus, the chosen platform for this case study is by its very nature more conservative in both its upstream technology platforms, and in its forecasted dose requirements of 2500 doses/year per regional manufacturing center.

The facility was modeled on a real-world case study manufacturing center in the UK with approximately $90 \mathrm{M}^{2}$ of cleanroom space as a starting configuration for the COG model (Figure 2). Cleanroom space was expanded as required by the model depending on the predicted manufacturing hardware and space requirements for each specific case study.

This research case study focuses on monolayer expansion platforms. While these platforms are less scalable than technologies such as stirred tank reactors, they are still clinically relevant. Expansion in monolayer is often in the form of ten-layer cell factories, particularly for MSCs, yet as this research aimed to examine automated solutions that were able to take the place of a human operator for certain unit operations (the SelecT platform), automation-compatible flask-based culture was selected as a convenient trade-off. As technologies such as stirred tank reactors complete process development steps and move toward mainstream adoption, they are likely to have a transformative effect in reducing COG. At this stage, we envisage these technologies will begin to be progressively automated and follow-up studies based off the template provided here could be used to assess the implications of this automation on COG and quality.

\section{Results \& discussion}

\section{Culture environment}

The environment in which the cells are expanded has a profound impact on the overall growth kinetics. While vessel choice and format undoubtedly has a role to play [10], the choice of medium plays a significant role in the expansion and ultimately determines the lot sizes that are achievable in a given expansion cycle. Since the introduction of serum free or fully defined media such as Essential $8^{\text {TM }}$ for maintaining stem cells [29], as well as fully defined chemical conditions for differentiation [30], there has been a strong trend toward adoption of SFM [31]. 


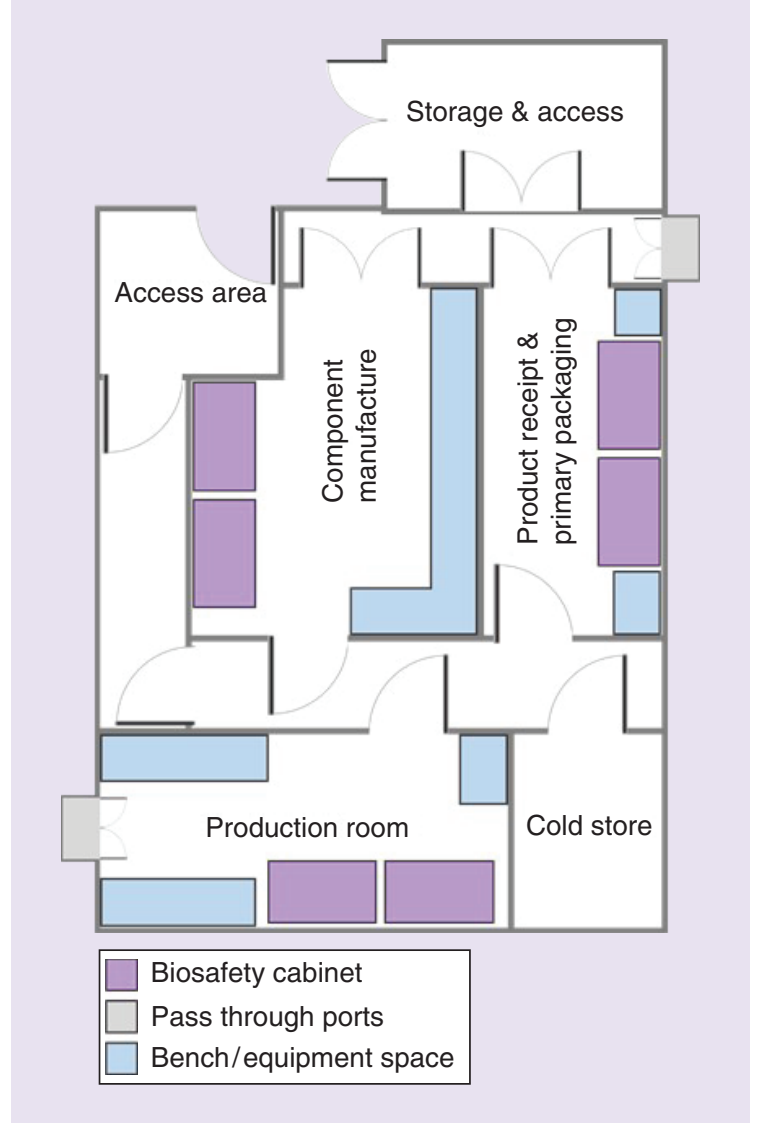

Figure 2. Cleanroom example used as a predicted estimate for the cost of goods model.

For the purposes of this case study, we assumed planar bioreactor formats and expanded three donor cell lines in automation-ready traceable T-175 flasks. MSCs from mononuclear cells were expanded over three passages in both FBS-containing media (SCM) and SFM and their growth kinetics used to extrapolate theoretical maximum cell yields (Figure 3A \& B). Maximum cell yields were plotted on a log scale due to the profound differences between SCM (Figure 3A) and SFM (Figure 3B). Maximum achievable lot sizes were observed to be two orders of magnitude greater in SCM compared with SFM. Moreover, the variation between batches was found to be decreased in SFM versus SCM.

The large discrepancies in growth rate between SFM and SCM translate directly into the COG and the relatively low growth rate or SCM prohibit cell doses of 1,000,000 cells $/ \mathrm{kg}$ body weight or higher. A dose size of 7,500,000 cells was examined for potential COG (Figure 3C). COG/dose of between US $\$ 3000$ and US $\$ 6000$ were observed for SCM preparations, although these estimates are conservative given the number of lots that need to be run in order to facilitate this number of doses per annum (Figure 3D). SFM-cultured cells not only had COG/dose of between US $\$ 1000$ and US $\$ 2000$ with far fewer lots required per year. It is also worth noting that the reproducibility afforded by SFM contributes to a tighter accuracy of predicated costs due to the enhanced reproducibility between differing donor cells.

These data also issue of the role of population doublings in establishing cell potency [32]. This study did not examine the relationship between indicators of potency and relative population doubling limits (PDLs) for both SFM and SCM cultures. It is, however, important to note that although the SFM conditions may yield a greater number of cells, in a real clinical scenario, this expansion potential may be limited by the effective number of PDLs before the cells lose the desired potency. Many submissions to the US FDA for clinical translation overlook the importance of PDLs [33] and when extrapolating potential costs, this issue should be considered as a key consideration beyond solely the expansion potential of the cells. 
(A)

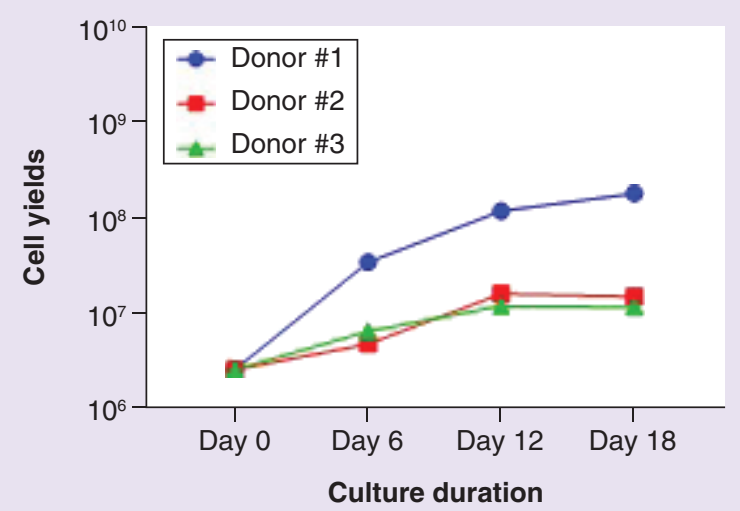

(C)

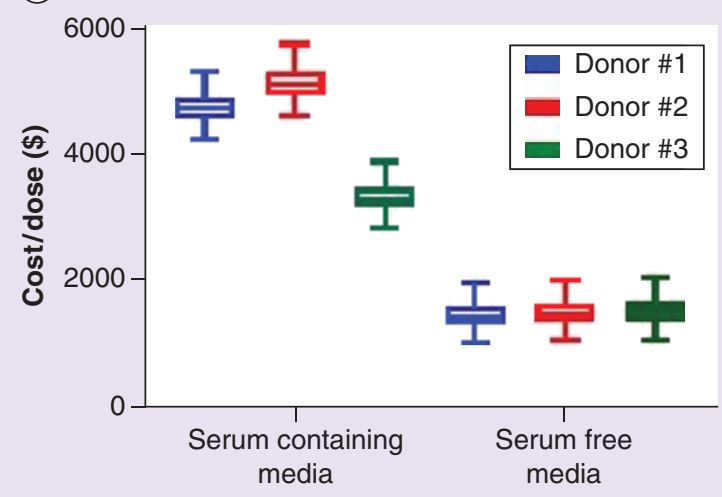

(B)

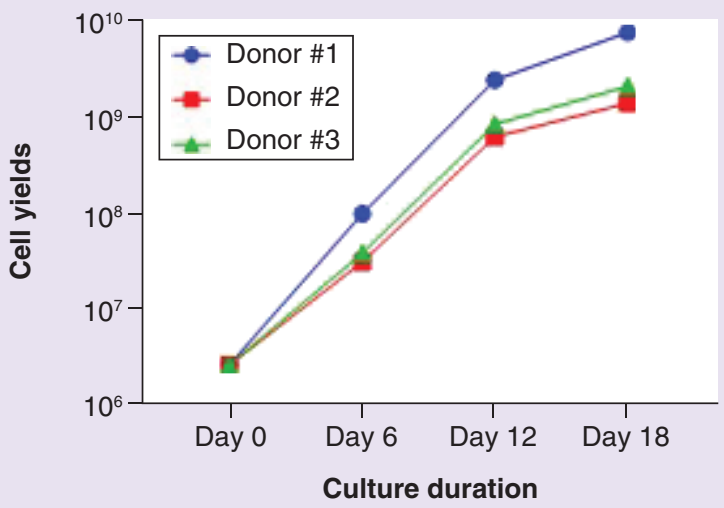

(D)

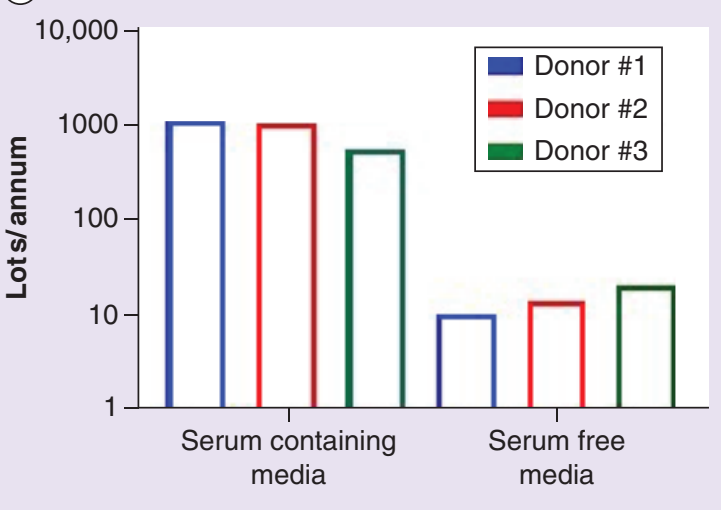

Figure 3. Growth kinetics of three donor-derived cell lines cultured in standard serum-containing medium and serum-free medium. Donor-derived cells expanded in SCM (A), reach lot sizes in order of magnitudes lower than SFM (B). This translates directly into the underlying COG (C) making dose sizes more than 7,500,000 cells/dose shown prohibitive. Due to reduced lot sizes, lots per annum were found to be dramatically higher for SCM versus SFM (D). COG: Cost of goods; SCM: Serum-containing medium; SFM: Serum-free medium.

\section{Impact of staffing on COG}

Staff costs are one of the largest costs to a business' day-to-day running. Even for high-value manufacturing, the impact of staff on fundamental COG cannot be overstated. Some of the interesting features of staffing trends in this example case study are presented in Figure 4.

While all staff are equally critical to keeping the 'machine' that is a functioning business running smoothly, not all staff are equal in their relative costs to the business or more accurately the associated liability for significant expenditure from training. Costs for specific staffing members, breaking down as: base salary, overheads such as pension and insurance contributions as well as training, can be seen to vary dramatically between different staff categories (Figure 4A). The stark differences between staff at differing levels of seniority are unsurprising, but the high training costs of operators have the potential to cause a significant increase in the staffing cost burden for conditions of high employee turnover. For the purposes of this case study, a low operator turnover of $10 \%$ per annum has been selected but, if this is increased, the relative contribution to cost of training each new operator increases dramatically, becoming a nonvalue adding element of the total COG (Figure 4B). For this reason, it will be prudent to research and model carefully the impact of good remuneration on production staff turnover.

The number of operators required to successfully operate a manufacturing facility has a direct impact on final product COG. As operator number increases, the final product COG increase (Figure 4C). Relative costs can be seen to be higher for the automated facility primarily due to increased capital expenditure costs. Savings would, however, likely be realized through reduced expenditure on staff as fewer operators are required to service the facility. In this example, a $45 \%$ reduction in operator numbers enabled by moving to the SelecT (Sartorius Stedim)-automated 
(A)

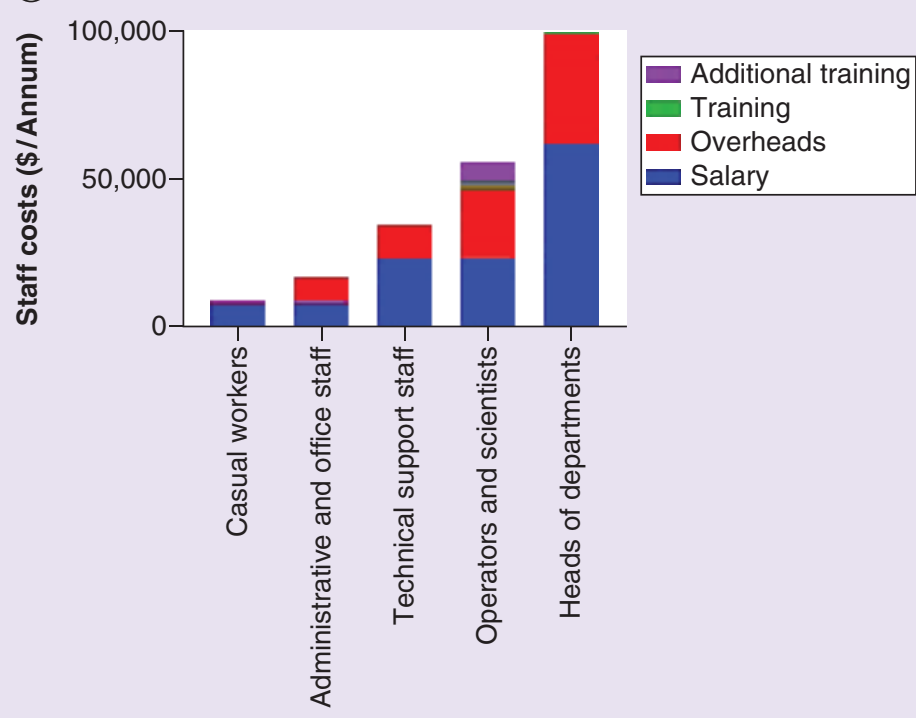

(c)

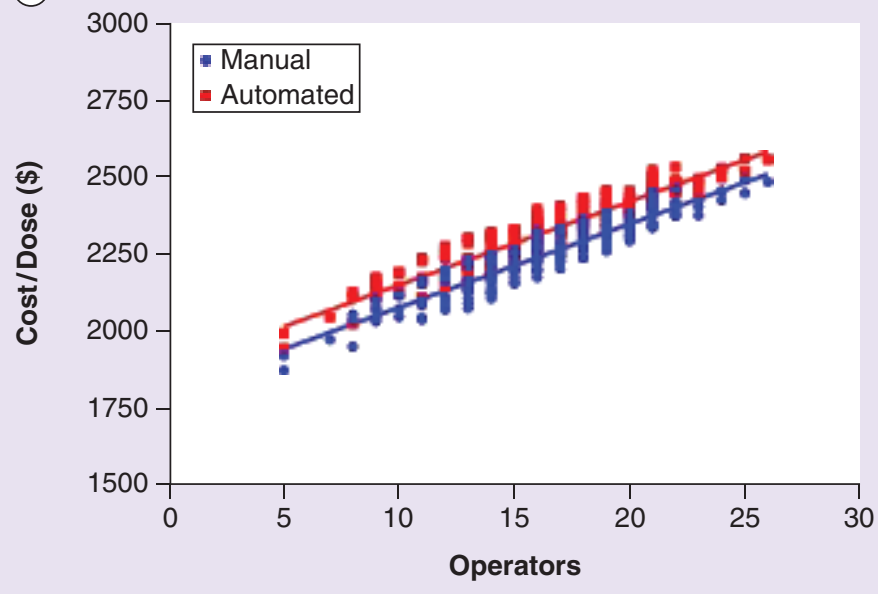

(B)

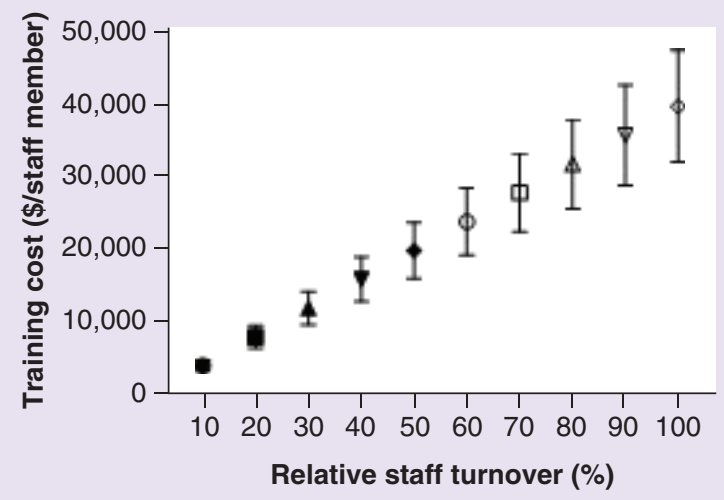

(D)

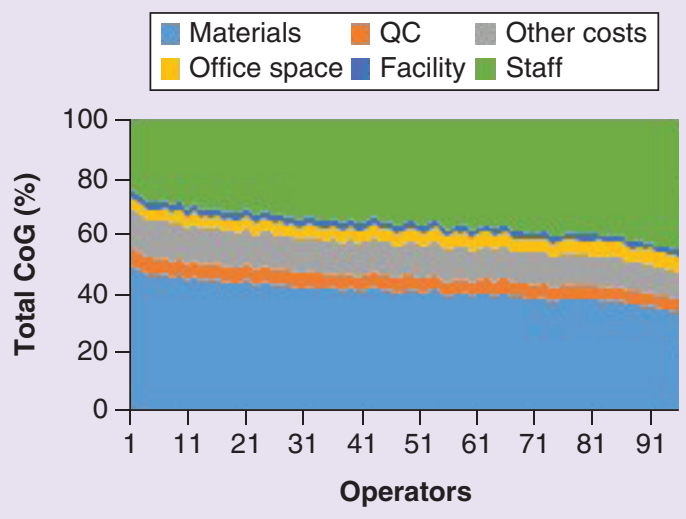

Figure 4. The costs of staff to a cell-manufacturing business. Not all staff are equal: a breakdown of specific, individual staffing member costs (A) highlights differences, particularly in training for operators. Training of operators can be particularly costly and if staff turnover is high, this dramatically increases training costs per operator (B). When examining differing configurations of operator salary bands (C), there is some overlap between overall COG between the manual and automated facilities. With the added linear regression, there is, however, a clear increase in overall cost of automated facilities versus manual. Materials and staff can be seen to be the predominant determinants of cost (D).

COG: Cost of goods; QC: Quality control.

platform would still yield $8 \%$ savings on total COG. The overall impact of operator staff costs relative to other constituents is presented (Figure 4D). Once operator staff numbers exceed approximately 65, this cost becomes a greater burden than the wet consumable costs for this manufacturing paradigm.

\section{Donor variability}

Variation can be introduced to processes through multiple avenues. These include reagents, process inconsistencies (particularly highly manual processes), shipping and storage of materials and biological donor variability. Attempts to reduce this variability through clearer provenance of reagents [31], enhancement of shelf-lives [17] and automation of manual processes [26] have reduced the incidence of variation, yet donor variability remains a key contributor to process variability [34]. 


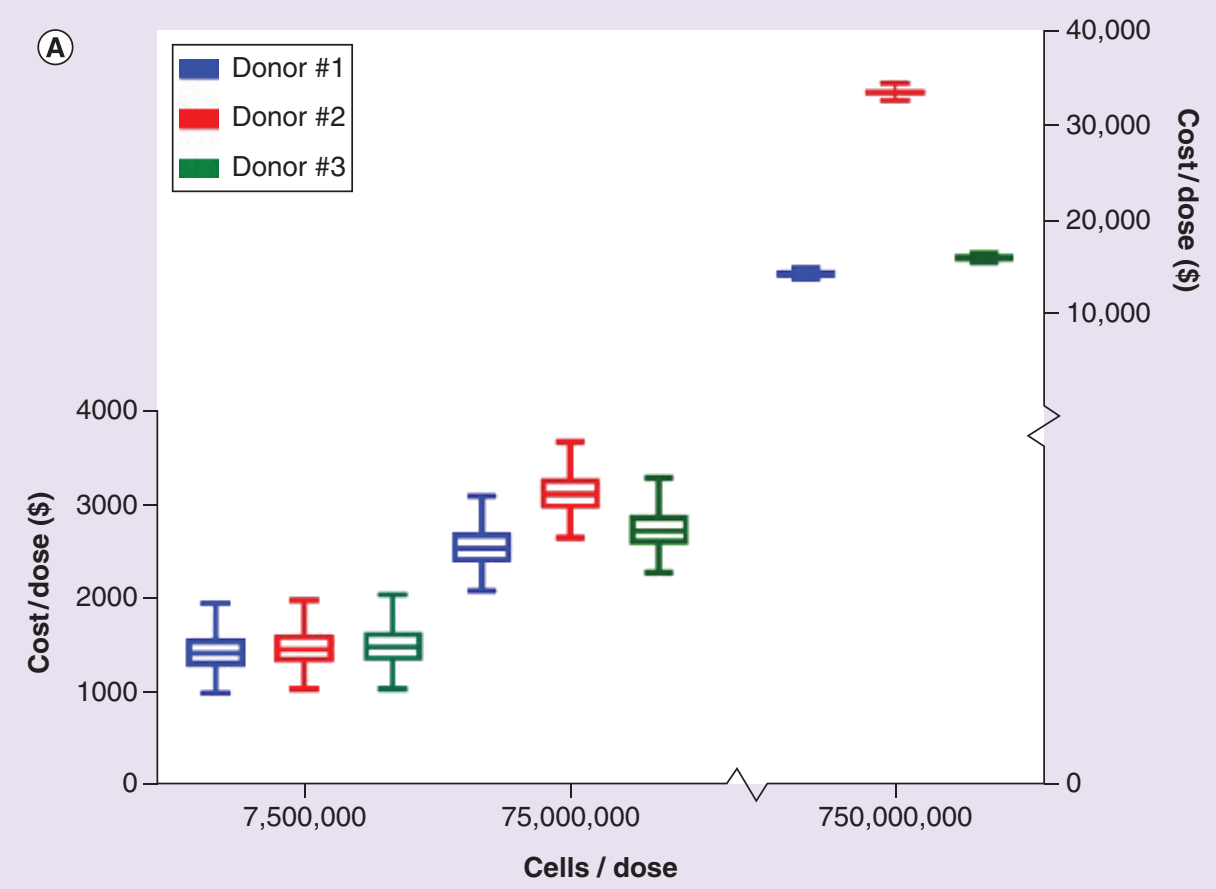

(B)

(C)
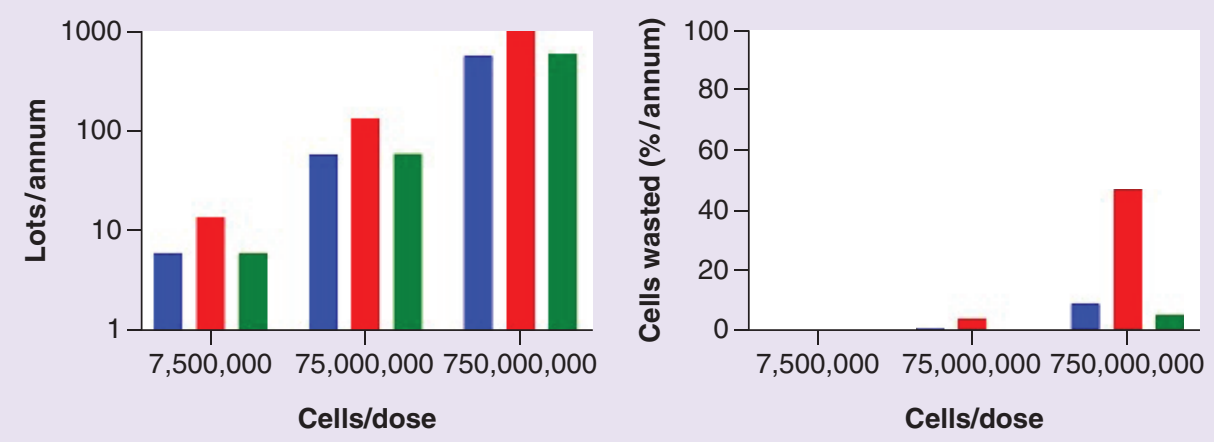

Figure 5. The impact of three donor-derived cell lines on the efficiency of the manufacturing value chain. Smaller dose sizes result in a lower COG/dose while larger dose sizes are clearly unfeasible with this production platform (A). As dose size increases, the number of lots required to produce them increases dramatically beyond what would be achievable in a predominantly manual facility (B). An indirect effect of increasing dose sizes is cell wastage through inefficient dose splitting per lot (C).

COG: Cost of goods.

Cells isolated from patients for manufacturing purposes have a limited expansion potential and thus provide little margin for multigenerational lineage selection of specific subpopulations [35]. The need constantly to refresh the cell bank means that multiple donors must be found and qualified with concomitant variability. This donor-to-donor variability is an inherent aspect of utilizing adult stem cell sources for manufacturing and presents its own array of challenges particularly around the logistical burden, input variation and QC [11]. Of primary concern is the impact that this substantial variability has on the manufacturing process and how far that process can be adapted to accept sources with wide input variation. While donor variability has a profound impact on the technical development of manufacturing processes, it also plays a role in the efficiency of the manufacturing chain, which can be explored by examining the COG (Figure 5).

It is perhaps obvious that expansion potential of cells is tied directly to the cost of producing them, cells that grow more rapidly with fewer allocated resources are cheaper to produce. This is, however, a simplistic view of the 
picture. Each dose formulation is a division of the size of the lot, which produce it. If fewer cells are wasted from each lot, a lower COG/dose can be obtained as summarized in Figure 5A. As dose size increases, the number of doses which can be produced from a given lot size decreases. This flask-based production methodology is evidently unsuitable for manufacturing high single-dose cell numbers as the costs quickly become prohibitive in Figure 5A.

The expansion potential of the cells also plays a role as less vigorous cells (as evidenced by Donor\#2) produce fewer cells per lot. As dose size increases, the number of lots to achieve the doses required increases dramatically beyond what is possible with even automated flask-based culture systems (Figure 5B). At dose sizes of 750,000,000 cells, the number of lots and flask manipulations that are required quickly become uneconomical. At high doses, this can be seen to have profound effects on the overall COG/dose (Figure 5A). This significant effect is primarily due to decreased efficiency of doses produced per lot and subsequently increasing numbers of discarded cell product (Figure 5C). If lot sizes are able to be better matched to patient doses, this cost burden of cell wastage could be addressed. This would, however, require an enhanced understanding of biological variability and a means to rapidly extrapolate future growth potential of donor material early on in the process.

\section{QC \& transport}

Screening of donor material and QC testing of final product have the potential to add significantly to the overall final product COG. Similarly, final formulation and subsequent shipping format impacts dramatically on the final product COG [11].

Cryogenic transport has been the mainstay of cell-shipping options [36] and perhaps unsurprisingly this more mature format is significantly cheaper than the shipping of fresh preparations (Figure 6A). There is a trend regardless of facility staffing types: fresh-preserved goods are approximately US $\$ 400$ more expensive than cryogenically shipped products (Figure 6B). This calculation does not factor in the increased risk of product being discarded due to a failure in supply chain, surgical team or the patient. This has a higher probability with fresh-shipped product and estimates into freshly shipped tissue-engineered products have put losses at an average of $45 \%$ [37], which would place fresh-shipped product COG at approximately $150 \%$ more expensive that frozen.

The level of QC performed on a product is vital for providing adequate quality assurance to maintain safety margins [38]. Secondary to this is the role testing can play in process control. For the calculations within the model thus far, QC has been based on the best practice assays currently in normal use [38], namely, marker analysis, PCR, differentiation assays and cell potency assays. There are, however, a number of emerging technologies, which have the potential to dramatically change the way that we evaluate cell-based products using assays that employ a small number of parameters (the 'measurands') to act as surrogates for the set of critical quality attributes that are of interest for batch release. These 'smart sensors' require calibration using a literal library of information from which we can pull the complex and interrelated factors which, within the bounds of the control strategy, can be relied upon to show the true makeup of a cell product.

Next-generation sequencing-based technologies have already dramatically fallen in price from their initial levels of approximately US $\$ 300$ million in 1999 [39] and US $\$ 100$ is promised in the 'near' future [40]. It is only really since 2009 that these technologies have fallen to the level where they may be used routinely. COG trends for whole-genome analysis were obtained from the NIH National Human Genome Research Institute and subsequent COG for a cell-based therapy were examined (Figure 6C). Since 2011, next-generation sequencing technology prices have fallen to a level where they have the potential to integrate into routine QC of manufactured cell-based therapies. Indeed, if we examine the final COG percentages, in 2009 this would have been nearly $70 \%$ of total COG, while if we were looking to integrate this technology into QC processes today, it would be analogous to a minor constituent such as fill and finish.

\section{Conclusion}

This case study was established as a pilot for examining small-scale manufacturing of emerging cell therapies. While the industry has long awaited the 'blockbuster' therapeutic to rival the pharmaceutical and biologics industries, the success stories for cell and gene therapies have been small scale and driven primarily through clinical engagement. With increasing strategies to enable smaller-scale local manufacturing [41], the possibility of a facility that produces relatively low numbers of high-value products as a stepping stone toward large-scale manufacture is looking increasingly feasible.

The process steps utilized in this case study, while broadly applicable to general cell manufacturing, will change depending on the exact process being considered. With the intense activity and early clinical success of chimeric 
(A)

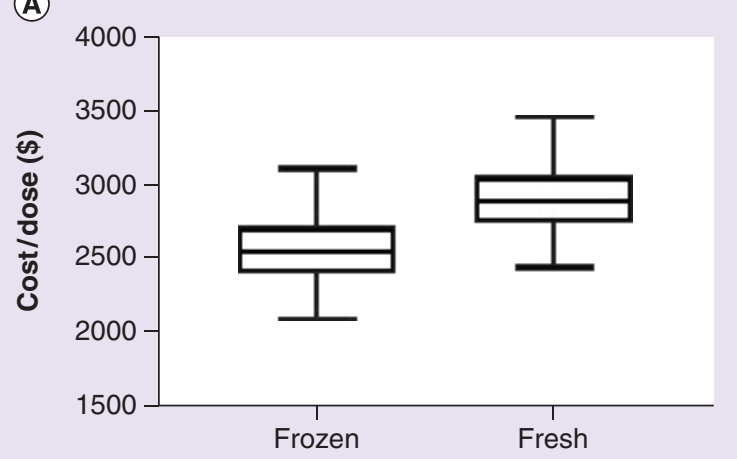

Final formulation type

(C)

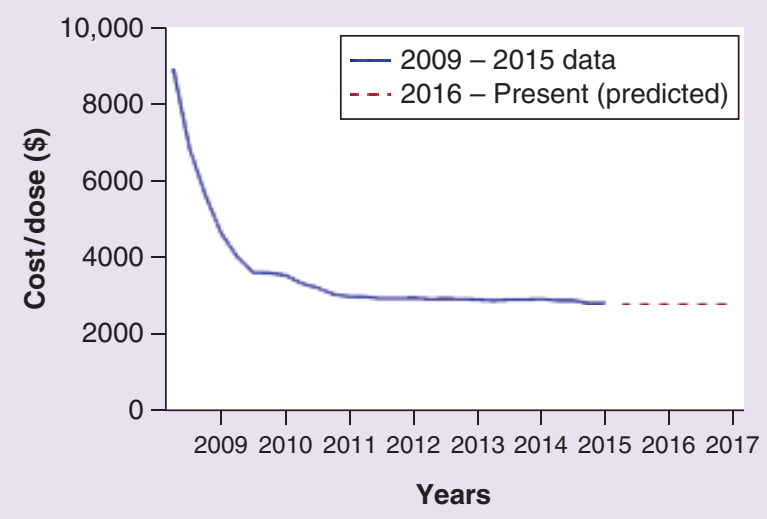

(B)

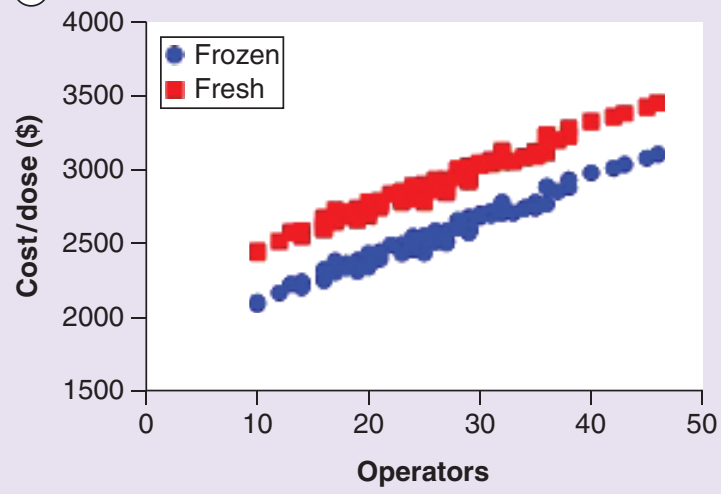

(D)

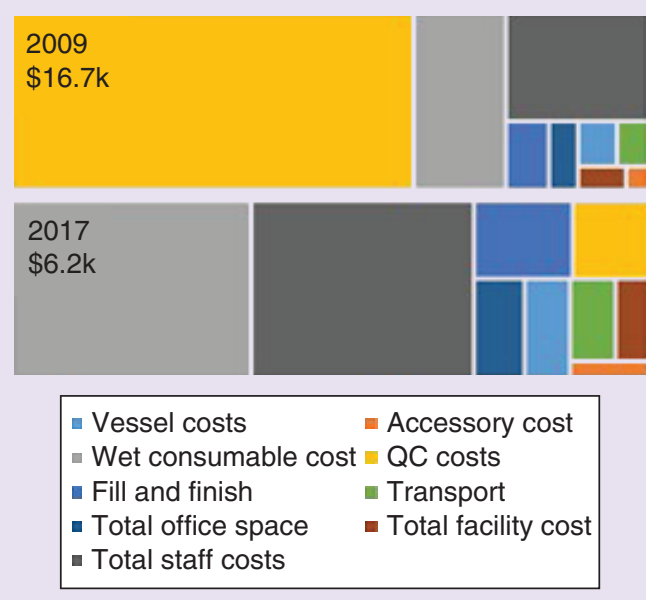

Figure 6. The effect of product transport options and emerging quality control opportunities on final cost of goods. Final formulation can be seen to have a profound impact on total COG/dose (A) and this trend is clear regardless of the facility/operator setup (B).

Next-generation sequencing cost trends for QC were examined over time (C) and it is clear that while only in 2009, it would have been a prohibitively large percentage of COG, at present day prices, the cost versus reward gleaned from the enhanced QC and understanding is much lower (D).

COG: Cost of goods; QC: Quality control.

antigen receptor T-cells, there is speculation about the expected process considerations for these cell types [42]. While the research presented here is broadly similar, there are likely to be extra process steps such as activation or gene modification for chimeric antigen receptor T-cells, which significantly increase complexity and handling. Additionally, the culture environment is likely to utilize platforms such as the WAVE ${ }^{\circledR}$, Miltenyi Prodigy ${ }^{\circledR}$ or G-Rex ${ }^{\circledR}$ bioreactors, the handling of which differ substantially from the automation steps presented here. These cell types would require a separate, bespoke analysis for which this study acts as a template.

Labor in this business model Is a large component of the overall spend and is a complex issue with potential to vary particularly due to training expenditure. Requalification of skills for lab operators can be considered an essential part of the business. However, staff turnover-related retraining is a nonvalue adding element of the organizational budget. This large recurring expense provides an opportunity to improve employee satisfaction, reduces staff turnover and subsequent disruption and cuts costs. While this cannot reduce turnover entirely, it could improve operational efficacy without undue additional financial expenditure.

The decision to replace human operators with automated handling platforms is at first glance a costly one due to the significant additional capital expenditure. However, when examined in detail, the argument for an automated facility versus a manual facility becomes more compelling. Significant reductions on operating expenditure may be made even with minor operator workforce reductions. As more capable automation platforms emerge, this saving in total COG is likely to be magnified further. In practice, it will be important to model carefully the 
level of backup staff employed in small facilities in order to prevent operator shortfall due to illness or demand spikes. It is pertinent to remember that in addition to cost savings, automated platforms contribute to enhanced reproducibility, which, in turn, instils confidence in the final product [43,44]. Automation is not the only factor in this however. Three donor cell lines behaved markedly differently when cultured in serum versus in SFM. This improved standardization between donor cells in SFM allows costs to be predicted with a greater degree of accuracy. SFM was also found to be far superior from an expansion potential point of view and even though it is significantly more expensive, the additional reductions in reduced manipulations and batch frequency make it better from the perspective of improved margins. For this study, reagent values were estimated to be more costly than academic reagents, yet the picture is not always clear. When moving from development to clinical and then commercial scale manufacturing, costs for reagents can be reduced by roughly $30 \%$ or increase by as much as $300 \%$. This increase in cost is largely driven by the requirement for traceability and provenance of the supply chain. Conversely, reduction in cost is potentially partly driven by economies of scale (although the effect of scale in cell manufacturing is low compared with other industries), and partly by a reduction in product margin driven by an increase in purchasing power (Heathman T, Pers. Comm., 11th October 2017).

Choice of transport method will have a profound impact on the success of cell-based therapeutics. Cryogenic transport, as a mature technology, is cheaper than to ship freshly prepared product at $37^{\circ} \mathrm{C}$. There are also additional cost burdens to fresh transport that are less evident. The $45 \%$ loss of product for a keratinocyte-derived graft [37] undoubtedly contributed to the lack of commercial success and lessons can be learnt from this. Frozen transport may be cheaper now, but with improved supply chain logistics, fresh could become increasingly viable.

Next-generation sequencing technologies have the potential to revolutionize personalized medicine through better understanding of the genome and the efficacy of treatments to these genomic variations. This increased understanding also translates well to manufacturing, allowing us to build up an increasingly detailed understanding of the product, which will, in turn, allow specific manufacturing process improvements to be implemented. This would instill greater confidence in the quality of the final cell-based therapeutic through improved QC.

Examining the granular economic detail of the manufacturing value chain allows judgments to be made early on in the business-planning stage and priority can then be given to candidates with a high probability of adoption. We underscore the importance that should be given to reproducibility and highlight two methods that are important, cost-effective drivers for enhancing reproducibility in the manufacturing process: namely, adoption of automation and SFM. Reliable, loyal staff are critical to business success, but small-manufacturing operations must be careful not to overcommit to large numbers of manual operations. The workforce should be augmented by automated platforms and savings used to maintain high levels of training and worker satisfaction as staff turnover is a significant nonvalue adding cost to the business.

As the field evolves, QC measures are becoming more advanced and cheaper to deploy. We are reaching the point where large-scale -omics screening is possible routinely. Combined with advances in automation, we believe these technologies act as a significant enabler to successfully navigating the regulatory landscape. By understanding the importance of these tools from not only a biological and regulatory perspective but also how their commercial viability dictates their use, we can facilitate better commercial planning.

Although this paper focuses on the cost of manufacturing cell therapies, it is important to realize that this is only one component of the commercialization pathway. From inception of a cell therapy product concept through to commercial launch, a number of steps must be successfully navigated including basic process development steps, preclinical development, assay development, clinical manufacturing, market approval and reimbursement. Understanding COG is only a small component of this pathway, yet examining this critical component early on in the development can help distinguish processes suitable for development and small-scale clinical manufacture from those adequate for commercial-scale manufacture.

Supplementary data

To view the supplementary data that accompany this paper please visit the journal website at: www.futuremedicine.com/doi/sup $\mathrm{pl} / 10.2217 / \mathrm{rme}-2017-0103$ 


\section{Summary points}

\section{Historical perspectives}

- The pharmaceutical industry has been truly transformative for human health and wealth creation, but like regenerative medicine, it too experienced severe 'growing pains'.

- The lack of a blockbuster therapy should not deter investment in smaller capacity, which can facilitate life-changing clinical outcomes for patents.

Process economic modeling

- Modeling approaches can be used to identify the most promising cell therapy candidates not only on clinical efficacy but ease of manufacture.

- Hypothesized optimal-manufacturing paradigms can be tested to establish sound strategies early on in development.

- A process economics model was developed to examine an adherent cell-manufacturing paradigm comparing manual versus automated planar processes.

Results

- Donor variability makes matching lot sizes to culture vessels challenging, which can increase cell wastage and thus total cost of goods (COG).

- The expansion potential of differing donor cell types is directly linked to the cost of manufacture.

- Operator labor constitutes a large component of overall COG for manufacturing.

- Quality control approaches which comprise advanced omics-type screening have become significantly more cost efficacious over the last 8 years.

Conclusion

- Producing low numbers of high-value products as a stepping stone toward large-scale manufacture is arguably a feasible approach.

- The pressure to automate is strong for both reducing COG and increasing replicability.

- The total contributions of quality control to COG are significant but manageable if split over multiple patient doses.

\section{Acknowledgements}

The authors acknowledge the support of the Redistributed Manufacturing in Healthcare Network (RiHN) for their support in coordinating expert meetings.

\section{Disclosure}

The opinion reflected in this report is the opinion of the authors and their interpretation and aggregation of the opinion of the individual thought leaders as members of a selected expert reference panel. It does not represent the views of their employers or any organizations they may represent.

Financial \& competing interests disclosure This study was supported by an EPSRC ETERM Landscape Fellowship grant (R Harrison) reference EP/1017801/1 and an EPSRC Fellowships in manufacturing grant (N Medcalf) reference EP/K037099/1. The authors have no other relevant affiliations or financial involvement with any organization or entity with a financial interest in or financial conflict with the subject matter or materials discussed in the manuscript apart from those disclosed.

No writing assistance was utilized in the production of this manuscript.

\section{Ethical conduct of research}

The authors state that they have obtained appropriate Institutional Review Board approval or have followed the principles outlined in the Declaration of Helsinki for all human or animal experimental investigations. In addition, for investigations involving human subjects, informed consent has been obtained from the participants involved.

\section{Open access}

This work is licensed under the Creative Commons Attribution 4.0 License. To view a copy of this license, visit http://creativecommons.org/licenses/by/4.0/ 


\section{References}

1. Mason C, Dunnill P. A brief definition of regenerative medicine. Regen. Med. 3(1), 1-5 (2008).

2. Thomas ED, Lochte HL, Cannon JH, Sahler OD, Ferrebee JW. Supralethal whole-body irradiation and isologous marrow transplantation in man. J. Clin. Invest. 38, 1709-1716 (1959).

3. Petersdorf EW, Gooley TA, Anasetti C et al. Optimizing outcome after unrelated marrow transplantation by comprehensive matching of HLA class I and II alleles in the donor and recipient. Blood 92(10), 3515-3520 (1998).

4. Karantalis V, Schulman IH, Balkan W, Hare JM. Allogeneic cell therapy: a new paradigm in therapeutics. Circ. Res. 116(1), 12-15 (2015).

5. Trounson A, McDonald C. Stem cell therapies in clinical trials: progress and challenges. Cell Stem Cell 17(1), 11-22 (2015).

6. Caplan A. Adult mesenchymal stem cells for tissue engineering versus regenerative medicine. J. Cell. Physiol. 341-347 (2007).

7. Le Blanc K. Immunomodulatory effects of fetal and adult mesenchymal stem cells. Cytotherapy 5(6), 485-489 (2003).

8. Uccelli A, Moretta L, Pistoia V. Mesenchymal stem cells in health and disease. Nat. Rev. Immunol. 8(9), 726-736 (2008).

9. Caplan AI, Dennis JE. Mesenchymal stem cells as trophic mediators. J. Cell. Biochem. 98(5), 1076-1084 (2006).

10. Rafiq QA, Brosnan KM, Coopman K, Nienow AW, Hewitt CJ. Culture of human mesenchymal stem cells on microcarriers in a $5 \mathrm{~L}$ stirred-tank bioreactor. Biotechnol. Lett. 35(8), 1233-1245 (2013).

11. Heathman TRJ, Nienow W, Mccall MJ, Coopman K, Kara B, Hewitt CJ. The translation of cell-based therapies: clinical landscape and manufacturing challenges. Regen. Med. 10, 49-64 (2015).

12. Mack GS. Osiris seals billion-dollar deal with Genzyme for cell therapy GM poplars to grow next door. Nat. Biotechnol. 27(2), 106-107 (2009).

13. Dodson BP, Levine AD. Challenges in the translation and commercialization of cell therapies. BMC Biotechnol. 15, 70 (2015).

14. Allison M. Genzyme backs osiris, despite prochymal flop. Nat. Biotechnol. 27(11), 966-967 (2009).

15. Lysaght MJ, Hazlehurst AL. Tissue engineering: the end of the beginning. Tissue Eng. 10(1-2), 309-320 (2004).

16. Dimasi JA, Grabowski HG, Hansen RW. Innovation in the pharmaceutical industry: new estimates of R \& D costs. J. Health Econ. 47, 20-33 (2016).

17. Ratcliffe E, Thomas RJ, Williams DJ. Current understanding and challenges in bioprocessing of stem cell-based therapies for regenerative medicine. Br. Med. Bull. 100(1), 137-155 (2011).

18. Simaria AS, Hassan S, Varadaraju $\mathrm{H}$ et al. Allogeneic cell therapy bioprocess economics and optimization: single-use cell expansion technologies. Biotechnol. Bioeng. 111(1), 69-83 (2014).

19. Golpanian S, Schulman IH, Ebert RF et al. Concise review: review and perspective of cell dosage and routes of administration from preclinical and clinical studies of stem cell therapy for heart disease. Stem Cells Transl. Med. 5(2), 186-191 (2016).

20. Hou D, Youssef EA-S, Brinton TJ et al. Radiolabeled cell distribution after intramyocardial, intracoronary, and interstitial retrograde coronary venous delivery: implications for current clinical trials. Circulation 112(9 Suppl.), I150-I156 (2005).

21. Hamamoto H, Gorman JH, Ryan LP et al. Allogeneic mesenchymal precursor cell therapy to limit remodeling after myocardial infarction: the effect of cell dosage. Ann. Thorac. Surg. 87(3), 794-801 (2009).

22. Premer C, Blum A, Bellio MA et al. Allogeneic mesenchymal stem cells restore endothelial function in heart failure by stimulating endothelial progenitor cells. EBioMedicine 2(5), 467-475 (2015).

23. Atala A, Allickson JG. Translational Regenerative Medicine (1st Edition). Elsevier, Amsterdam, The Netherlands (2014).

24. McGuckin C, Jurga M, Ali H, Strbad M, Forraz N. Culture of embryonic-like stem cells from human umbilical cord blood and onward differentiation to neural cells in vitro. Nat. Protoc. 3(6), 1046-1055 (2008).

25. Ge J, Guo L, Wang S et al. The size of mesenchymal stem cells is a significant cause of vascular obstructions and stroke. Stem Cell Rev. Reports 10(2), 295-303 (2014).

26. Rafiq QA, Twomey K, Kulik M et al. Developing an automated robotic factory for novel stem cell therapy production. Regen. Med. 11(4), 351-354 (2016).

27. Mason C, Dunnill P. A brief definition of regenerative medicine. Regen. Med. 3(1), 1-5 (2008).

28. Rowley J, Abraham E, Campbell A, Brandwein H, Oh S. Meeting lot-size challenges of manufacturing adherent cells for therapy. Bioprocess International (2012). www.bioprocessintl.com/manuf acturing/cell-therapies/meeting-lot-size-challenges-of-manufacturing -adherent-cells-for-therapy-328093/

29. Chen G, Gulbranson DR, Hou Z et al. Chemically defined conditions for human iPS cell derivation and culture. Nat. Methods. 8(5), 424-429 (2011).

30. Burridge PW, Matsa E, Shukla P et al. Chemically defined generation of human cardiomyocytes. Nat. Methods 11(8), 855-860 (2014).

31. Chu L, Robinson DK. Industrial choices for protein production by large-scale cell culture. Curr. Opin. Biotechnol. 12(2), 180-187 (2001). 
32. Liao H-T, Chang K-H, Jiang Y, Chen J-P, Lee M-Y. Fabrication of tissue engineered PCL scaffold by selective laser-sintered machine for osteogeneisis of adipose-derived stem cells. Virtual Phys. Prototyp. 6(1), 57-60 (2011).

33. Mendicino M, Bailey AM, Wonnacott K, Puri RK, Bauer SR. MSC-based product characterization for clinical trials: an FDA perspective. Cell Stem Cell 14(2), 141-145 (2014).

34. Heathman T, Rafiq Q, Chan A et al. Characterization of human mesenchymal stem cells from multiple donors and the implications for large scale bioprocess development. Biochem. Eng. J. 108, 14-23 (2016).

35. Hadjizadeh A, Doillon CJ. Directional migration of endothelial cells towards angiogenesis using polymer fibres in a $3 \mathrm{D}$ co-culture system. J. Tissue Eng. Regen. Med. 4(7), 524-531 (2013).

36. Moll G, Geißler S, Catar R et al. Cryopreserved or fresh mesenchymal stromal cells: only a matter of taste or key to unleash the full clinical potential of MSC therapy? Adv. Exp. Med. Biol. 951, 77-98 (2016).

37. Hernon CA, Dawson RA, Freedlander E et al. Clinical experience using cultured epithelial autografts leads to an alternative methodology for transferring skin cells from the laboratory to the patient. Regen. Med. 1(6), 809-821 (2006).

38. De Sousa PA, Downie JM, Tye BJ et al. Development and production of good manufacturing practice grade human embryonic stem cell lines as source material for clinical application. Stem Cell Res. 17(2), 379-390 (2016).

39. Kulski JK. Next-generation sequencing - an overview of the history, tools, and 'omic' applications. In: Next Generation Sequencing Advances, Applications and Challenges. Kulski JK (Ed.). InTech, Rijeka, Croatia, 3-60 (2016).

40. Anderson C. Data deluge: researchers turn to cloud computing as genomic sequencing data threatens to overwhelm traditional IT Systems. Clin. Omi. 4(1), 26-29 (2017).

41. The Medicines Manufacturing Industry Partnership. Advanced therapies manufacturing action plan. www.abpi.org.uk/our-work/mmip/Documents/Advanced-Therapies-Manufacturing-Taskforce-report.pdf

42. Wang X, Rivière I. Clinical manufacturing of CAR T cells: foundation of a promising therapy. Mol. Ther. Oncolytics 3, 16015 (2016).

43. Harrison RP, Rafiq QA, Medcalf N. Automating decentralized manufacturing of cell \& gene therapy products. Cell Gene Ther. Insights 2(1), 115-120 (2016).

44. Thomas R, Chandra A, Hourd P, Williams D. Cell culture automation and quality engineering: a necessary partnership to develop optimized manufacturing processes for cell-based therapies. J. Assoc. Lab. Autom. 13(3), 152-158 (2008). 